\title{
Blood tryptase and thymic stromal lymphopoietin levels predict the risk of exacerbation in severe asthma
}

\section{Shih-Lung Cheng}

Far Eastern Memorial Hospital

Ching-Hsiung Lin

Changhua Christian Hospital

Sheng-Hao Lin

Changhua Christian Hospital

Yi-Han Hsiao

Taipei Veterans General Hospital

\section{Kang-Cheng Su}

Taipei Veterans General Hospital

Chong-Jen Yu

National Taiwan University Hospital

Hao-Chien Wang

National Taiwan University Hospital

Chau-Chyun Sheu

Kaohsiung Medical University

Kuo-Chin Chiu

Luodong Poh-Ai Hospital

Diahn-Warng Perng ( $\nabla$ dwperng@vghtpe.gov.tw)

Taipei Veterans General Hospital

Hsin-Kuo Ko

Taipei Veterans General Hospital

\section{Research Article}

Keywords: asthma, eosinophils, exacerbation, thymic stromal lymphopoietin, tryptase

Posted Date: December 2nd, 2020

DOI: https://doi.org/10.21203/rs.3.rs-109575/v1 
License: (c) (i) This work is licensed under a Creative Commons Attribution 4.0 International License. Read Full License

Version of Record: A version of this preprint was published at Scientific Reports on April 19th, 2021. See the published version at https://doi.org/10.1038/s41598-021-86179-1. 


\section{Abstract}

Some patients with severe asthma experience exacerbations despite receiving multiple therapy. The risk of exacerbation and heterogeneous response to treatment may be associated with specific inflammatory molecules that are responsive or resistant to corticosteroids. We aimed to identify the independent factors predictive for the future risk of exacerbation in patients with severe asthma. In this multi-center prospective observational study, 132 patients with severe asthma were enrolled and divided into exacerbation $(n=52)$ and non-exacerbation $(n=80)$ groups on the basis of exacerbation rate after a 1year follow-up period. We found that previous history of severe-to-serious exacerbation, baseline blood eosinophil counts ( $\geq 291 \mathrm{cells} / \mathrm{mL})$, and serum tryptase $(\leq 1448 \mathrm{pg} / \mathrm{mL})$ and thrymic stromal lymphopoietin (TSLP) levels $(\geq 25 \mathrm{pg} / \mathrm{mL}$ ) independently predicted the future development of exacerbation with adjusted odds ratios (AOR) of 3.27, 6.04, 2.53 and 8.67, respectively. Notably, the patients with high blood eosinophil counts and low tryptase levels were likely to have more exacerbations than those with low blood eosinophil counts and high tryptase levels (AOR 16.9). TSLP and tryptase levels may be implicated in steroid resistance and responsiveness in the asthma inflammatory process. High blood eosinophil counts and low serum tryptase levels predict a high probability of future asthma exacerbation.

\section{Introduction}

Asthma exacerbation is associated with an increase in respiratory symptoms and progressive decrease in lung function ${ }^{1}$. In patients with severe asthma, $30 \%$ of subjects are frequent exacerbators, and these exacerbations impose a huge economic and health burden on health care systems ${ }^{2-4}$. Identifying disease characteristics and selecting effective treatment for patients with severe asthma are important to reduce the future risk of exacerbations ${ }^{5}$. Clinical phenotypes have been described but do not necessarily reflect underlying disease mechanisms ${ }^{6}$. The classification of endotypes have been developed to characterize distinct biological mechanisms, and thus therapy targeting specific molecules could improve disease outcomes in severe asthma ${ }^{7-10}$. Theoretically, endotype-related molecular/cellular biomarkers may be associated with the responsiveness to corticosteroids and could be applied to predict the future risk of exacerbation in patients with severe asthma ${ }^{9,10}$.

The inflammatory mechanism of asthma is currently divided into type 2 high and type 2 low (non-type 2) inflammatory processes. Type 2 high inflammation includes both allergic and non-allergic eosinophilic processes $^{8,10,11}$. In allergic asthma, exposure to an allergen results in the production of interleukin (IL)-4, IL-5, and IL-13 by T helper 2 lymphocyte $\left(T_{H} 2\right)$. The cytokines of IL- 4 and IL-13 stimulate B lymphocytes to produce antigen-specific immunoglobulin (Ig) $\mathrm{E}$ that drives the allergic cascade. IL-5 can increase the production, differentiation, maturation and activation of eosinophils. In non-allergic eosinophilic asthma, type 2 innate lymphoid cells (ILC2) appear to be responsible for the production of type 2 cytokines IL- 5 and IL-13. Accumulating evidence shows that $T_{H} 2$ cells and $T_{H} 2$-driven eosinophilia are usually 
responsive to glucocorticoids ${ }^{12-14}$. Clinically, a substantial proportion of patients with asthma does not respond to glucocorticoids very well ${ }^{15}$.

Thymic stromal lymphopoietin (TSLP), which is mainly derived from epithelium, can promote the activation of dendritic cells and $B$ lymphocytes as well as $T_{H} 2$-associated cytokine production ${ }^{16}$. TSLP can also induce chemotaxis and delay apoptosis in eosinophils, suggesting its potential role in allergic inflammation ${ }^{17}$. In addition, TSLP exerts a corticosteroid-resistant effect in natural helper cells by controlling STAT5 phosphorylation and BCL-xL expression ${ }^{18}$. As the major protein component in the mast cells, tryptase has been recognized as a specific marker of mast cell activation and involved in allergic asthm ${ }^{19}$. Serum tryptase can be used to predict disease severity in childhood asthma ${ }^{20}$. In induced sputum, tryptase concentration can be reduced by high doses of inhaled corticosteroid (ICS) within $6 \mathrm{~h}$ in symptomatic asthmatics ${ }^{21}$. Targeting the $\mathrm{T}_{\mathrm{H}} 2$ pathway can inhibit late asthmatic response by attenuating allergen-induced sputum eosinophilia and lowering tryptase levels ${ }^{22}$.

Eosinophils are involved in the pathogenesis of asthma exacerbation. Blood eosinophils are reportedly associated with the frequency of asthma exacerbation ${ }^{23}$. A UK cohort study found that asthmatics with blood eosinophil counts higher than 400 cells/ $\mu \mathrm{L}$ experience more severe exacerbations and poorer asthma control ${ }^{24}$. A treatment strategy specifically aimed to reduce sputum eosinophilia can decrease asthma exacerbation and hospitalization rate ${ }^{25}$. Collectively, the extent of eosinophilic inflammation appears to be associated with uncontrolled asthma. On the basis of these pieces of evidence, we hypothesized that clinical characteristics and inflammatory biomarkers may simultaneously affect patient outcomes and are independently associated with the future risk of exacerbation in patients with severe asthma.

We conducted a 1-year multicenter prospective observational study aimed to identify the clinical characteristics and useful biomarkers that can independently predict the risk of exacerbation in patients with severe asthma under maintenance treatment. We demonstrated that previous history of exacerbation, blood eosinophil count, and tryptase and TSLP levels can be used as independent factors for predicting future asthma exacerbations.

\section{Methods}

Study design. This prospective, observational, multi-center study was conducted at six hospitals across Taiwan from March 2016 to February 2018. The study was approved by the Institutional Ethical Review Board of Taipei Veterans General Hospital, Far Eastern Memorial Hospital, National Taiwan University Hospital, Changhua Christian Hospital, Kaohsiung Medical University Hospital and Lotung Poh-Ai Hospital (approval number: VGHTPE-IRB No. 2016-03-010AC) and conducted in accordance with the Declaration of Helsinki. All patients provided written informed consent for participation, and the study was registered at www.clinicaltrials.gov (NCT02871947). The patients enrolled were followed-up for 1 year after enrollment. 
Participants. Patients were outpatients aged 20-75 years with at least a 1-year history of asthma and a current diagnosis of severe asthma under GINA steps 4-5 therapy with a high-dose ICS ( $\geq 800 \mu \mathrm{g}$ of budesonide or equivalent) and a long-acting $\beta 2$ agonist, sustained-release theophylline or leukotriene receptor antagonist for the previous 6 months before enrollment or oral glucocorticosteroids (OCS) were prescribed in stable doses for the previous 3 months ${ }^{26}$. Patients were never smokers or had a smoking history of less than 10 pack-years. The main exclusion criteria were an event of asthma exacerbation treated with systemic glucocorticoids within 4 weeks before enrollment, chronic obstructive pulmonary disease, active malignancy, infectious diseases, active pulmonary tuberculosis, and a current treatment of home oxygen therapy $\geq 15 \mathrm{~h}$ per day and noninvasive positive pressure ventilation $\geq 6 \mathrm{~h}$ per day.

Measurements. The demographic information and clinical data including history of exacerbation, current treatment, atopy and comorbidities were collected. At the time of enrollment, the participants were assessed for Asthma Control Test (ACT); bronchodilator test according to the American Thoracic Society criteria $^{27}$; blood cell counts; fractional exhaled nitric oxide (FeNO); blood IgE; and associated mediators including interleukin IL-5, IL-13, periostin, tryptase, IL-8, IL-17, Tumor growth factor- $\beta$, vascular endothelial growth factor, placental growth factor, tumor necrosis factor-a, TSLP, and IL-33. The serum levels of cytokines and mediators were analyzed by Bio-Plex Suspension Array System with a validation kit control (\#64080422). Serum tryptase b-2 levels were measured by Human Tryptase/TPSAB1, B2 PicoKine ${ }^{\text {Tm }}$ ELISA Kit. (Catalog \#EK0898, Boster Biological Technology, Pleasanton CA, USA).

Definitions. Reversibility in the bronchodilator test was defined as an increase of $12 \%$ and $200 \mathrm{~mL}$ in $\mathrm{FEV}_{1}{ }^{1}$. Uncontrolled asthma was defined as at least one of the following: a) poor symptom control: $\mathrm{ACT}<20$; b) frequent severe exacerbations: two or more bursts of systemic OCS ( $>3$ days each) in the previous year; c) serious exacerbations: at least one hospitalization, intensive care unit stay or mechanical ventilation in the previous year; d) airflow limitation: after appropriate bronchodilator with forced expiratory volume in one second $\left(\mathrm{FEV}_{1}\right)<80 \%$ predicted and $\mathrm{FEV}_{1} /$ forced vital capacity $<0.7^{26}$. Severe exacerbation was defined as a worsening of asthma requiring the use of systemic corticosteroids for more than 3 days, whereas serious exacerbation was defined as requiring asthma-specific emergency department visits or hospitalization ${ }^{26}$. Atopic status was defined as the positive result of blood allergenspecific IgE. Previous history of asthma exacerbation was defined as the occurrence of severe or serious asthma within 1 year prior to the study entry. Electronic medical record and clinical information of asthma exacerbations throughout the follow-up period were assessed and recorded every 3 months.

Statistical analysis. Categorical variables were expressed as number (percentage) and evaluated by Chisquare test. Continuous variables with normal distribution were expressed as mean \pm standard deviation (SD) and evaluated by independent t-test. Continuous variables with non-normal distribution were expressed as median (interquartile range) and evaluated by Mann-Whitney $U$ test. Variables significantly associated with asthma exacerbation $(P<0.05)$ on univariate analysis were included in multivariate logistic regression analysis. The enter method was employed to identify the significant predictors. ROC analyses were performed to obtain area under curves (AUC) and the optimal cut-off values were 
determined by the largest values of Youndan's index with reliable sensitivity, specificity, positive predicted value, and negative predicted value for predicting asthma exacerbation. Finally, Kaplan-Meier survival curves were compared using the log-rank test to analyze the difference in time to severe-to-serious exacerbation between the study patients with and without an independent predictive factor. The power (1$\beta$ ) of the sample size was evaluated by G-power program. Results were considered significant at $P<0.05$ and all $p$ values were two-sided. Statistical analysis was performed using SPSS version 19.0 (SPSS Inc., Chicago, IL, USA).

\section{Results}

Demographic characteristics of study subjects. A total of 132 study subjects who fulfilled the criteria of severe asthma, including 82 females and 50 males with a median age of 62.5 (55.0-72.0) years, were recruited (Table 1). The median duration of asthma diagnosis was 5.0 (2.0-12.0) years. Among these participants, $29 \%$ had smoking history and $36 \%$ had a family history of asthma. Moreover, $55 \%$ of the study patients were atopic, and the median serum IgE level and blood eosinophil count were $101.0 \mathrm{IU} / \mathrm{mL}$ (30.1-320.0) and 187.6 cells/ $\mu \mathrm{L}(84.0-365.7)$, respectively. The most common comorbidities were allergic rhinitis, hypertension, and diabetes mellitus. The median FEV1 and FEV1\% pred were 1.45L $(0.96-2.05)$ and $65.3 \%(50.3-80.7)$, respectively, and $52 \%$ of the participants had fixed airflow limitation. Only $15 \%$ of the study subjects had positive bronchodilator reversibility and $7 \%$ of the patients received maintenance oral corticosteroids. The median score of ACT was 21 (19-23), 70\% of which were defined as uncontrolled asthma at the commencement of the study.

The study subjects were divided into two groups on the basis of the occurrence of severe-to-serious exacerbation after a 1-year follow-up period (Table 1). The exacerbation group $(n=52)$ had severe (1.13/year) and serious (0.71/year) exacerbation during the entire follow-up period compared with the non-exacerbation group $(n=80)$. Apparently, the history of severe exacerbation in the previous year were higher in the exacerbation group than that in the non-exacerbation group $(0.77 \pm 0.75$ vs. $0.44 \pm 0.70$, respectively; $p=0.003)$.

Blood biomarkers in both groups. The blood cellular and molecular biomarkers of the study subjects are summarized in Table 2. In terms of counts of blood eosinophils (absolute number $\geq 300$ cells/uL and more than $4 \%$ ) were significantly higher in the exacerbation group than those in the non-exacerbation group. Serum IgE, periostin, IL-5, and IL-13 levels, as well as FeNO, were not statistically different between the two groups. In particular, significantly lower tryptase levels and higher TSLP levels were observed in the exacerbation group ( $p=0.010$ and 0.016 , respectively) comparing with those in the non-exacerbation group.

Significant factors associated with asthma exacerbation. The significant factors associated with asthma exacerbation are listed in Table 3. The ROC curve was analyzed for blood eosinophil counts, and serum tryptase and TSLP levels to differentiate the exacerbation group from the non-exacerbation group (Supplementary Fig. 1A-1C). The adjusted multivariate logistic regression model revealed that previous 
history of severe-to-serious asthma exacerbation, serum tryptase level of $\leq 1448 \mathrm{pg} / \mathrm{mL}$, serum TSLP level of $\geq 25 \mathrm{pg} / \mathrm{mL}$ and blood eosinophil count of $\geq 291$ cells $/ \mathrm{uL}$, were the independent factors predictive for asthma exacerbation with an AOR of 3.27, 2.53, 8.67 and 6.04, respectively. The Kaplan-Meier curves of the cumulative probability of severe-to-serious exacerbation during the 1-year follow-up period stratified by the independent factors are shown in Fig. 1A-1D (all log rank test, $p<0.05$ ).

Adjusted odds ratio for future development of asthma exacerbation. The AOR for future development of asthma exacerbation associated with blood tryptase level and eosinophil count is shown in Fig. 2. Tryptase level of $1448 \mathrm{pg} / \mathrm{mL}$ and blood eosinophil count of 291 cells/ $\mathrm{uL}$ were considered as the cutoff. The patients with high eosinophil counts and low tryptase levels were more likely to develop asthma exacerbation that those with low eosinophil counts and high tryptase levels (AOR: $16.92,95 \% \mathrm{Cl}=3.88-$ $73.74, p<0.001)$.

\section{Discussion}

Asthma is a heterogeneous disease, and most of its clinical phenotypes cannot identify distinct entities. Biomarker analysis may help in tailoring treatment and predicting the future risk of exacerbation in patients with severe asthma ${ }^{5,28,29}$. In this prospective observational study, we demonstrated that previous history of severe-to-serious exacerbation, baseline serum tryptase and TSLP levels, and blood eosinophil counts could independently predict the future development of exacerbation in patients with severe asthma. Most importantly, patients with severe asthma with high blood eosinophil counts and low serum tryptase levels were more likely to have greater risk of exacerbation than those with low blood eosinophil counts and high serum tryptase levels despite treatment with ICS-contained multiple therapy. The present study was the first to analyze the biomarkers of severe asthma comprehensively and proposed the novel idea that the possible combination of elevated TSLP levels and reduced tryptase levels might result in ongoing eosinophilia and non-responsiveness to high-dose ICS treatment.

High blood eosinophil count is associated with disease severity and eosinophilic airway inflammation in asthma ${ }^{30}$. In the Copenhagen General Population Study, Signe el al. ${ }^{31}$ reported that increased incidence of moderate-to-severe exacerbation is more strongly associated with high blood eosinophil counts ( $>290$ cells $/ \mathrm{mL}$ ) than with low blood eosinophil counts ( $<180 \mathrm{cells} / \mathrm{uL}$ ). In the UK, Price et al. ${ }^{24}$ reported that patients with asthma with blood eosinophil counts $>400$ cells $/ \mu \mathrm{L}$ experience more severe exacerbations and have poorer asthma control. Our findings were consistent with these results. Absolute blood eosinophil counts of ${ }^{3} 291 \mathrm{cells} / \mathrm{mL}$ had a higher probability of asthma exacerbation (AOR $\left.=6.04\right)$. In addition, the patients with high blood eosinophil counts and low serum tryptase levels $(\leq 1448 \mathrm{pg} / \mathrm{mL})$ simultaneously suffered from more frequent exacerbations than those with low blood eosinophils and high tryptase levels (AOR up to 16.92).

Mast cells are tissue-based inflammatory cells of hematopoietic origin that respond to signals of innate and adaptive immunity. Mast cells play an important role in allergic diseases, including anaphylaxis, allergic rhinitis, and allergic asthma ${ }^{32}$. Human mast cells secrete $a$ - and $\beta$-tryptases. Mature $\beta$-tryptase, 
which was measured in this study, is the predominant form stored in the secretory granules of mast cells. Tryptase is a specific marker of mast-cell activation, and thus tryptase levels can be reasonably measured to reflect the burden of mast cell activation in the allergic $T_{H} 2$ pathway in asthma ${ }^{19,32}$. Gao et al. ${ }^{20}$ reported that serum baseline tryptase levels in childhood asthma, as well as asthma control, serum IgE and IL-13 levels, blood eosinophil counts, and lung function parameters, are strongly correlated with disease severity of asthma. The Severe Asthma Research Program also reported that severe asthma is associated with the predominance of tryptase+chymase+mast cells in the airway submucosa and epithelium $^{33}$. In addition, the gene expression of mast cell tryptase is increased in asthmatic epithelium, especially in the $T_{H} 2$-high subgroup, and predicts the responsiveness to $\mathrm{ICS}^{34}$. The numbers of airway tissue mast cells and the concentration of bronchoalveolar lavage tryptase can determine the efficacy of ICS treatment in persistent asthma ${ }^{35}$. The findings of our study were consistent with those of a previous study, which suggested that tryptase may be implicated in steroid responsiveness in the asthma inflammatory process and may determine the future risk of asthma exacerbation.

TSLP, which is produced mainly by the lung and gut epithelia, skin keratinocytes, and dendritic cells, is involved in various allergic diseases, including bronchial asthma, atopic dermatitis, and eosinophilic esophagitis. TSLP expression can be induced by several cytokines, respiratory viruses, bacterial and fungal products, allergens, cigarette smoke extracts, and tryptase ${ }^{36}$. In asthma, increased TSLP concentrations are observed in bronchoalveolar lavage, induced sputum, exhaled breath condensate, and plasma $^{37-40}$. TSLP expression is increased in the airway mucosa in a subset of severe asthmatics despite high-dose inhaled or oral steroid treatment ${ }^{41}$. TSLP can induce steroid resistance and abrogate the inhibitory effects of dexamethasone on type 2 cytokine production in ILC2 cells ${ }^{42}$. In the present study, we found that TSLP per se is an independent factor for predicting future risk of asthma exacerbation, and serum TSLP levels $\geq 25 \mathrm{pg} / \mathrm{mL}$ are associated with a high probability of asthma exacerbation (AOR = 8.19). Unsurprisingly, Corren et al. ${ }^{43}$ reported that anti-TSLP monoclonal antibody reduces annual exacerbation rates by $62 \%-71 \%$ at different doses in uncontrolled asthma despite treatment with long-acting b2 agonists and medium-to-high doses of ICS. Their findings have suggested some biological plausibility for TSLP being a contributor and an indicator of asthma exacerbation. Collectively, serum TSLP may contribute to steroid resistance, whereas tryptase may suggest steroid responsiveness in asthma inflammatory process, as observed in the present study. Moreover, our study suggested the novel idea that the possible combination of elevated TSLP levels and reduced tryptase levels might result in ongoing eosinophilia and non-responsiveness to high-dose ICS treatment. This combination of biomarkers (high TSLP levels and low tryptase levels) might indicate that these patients with severe asthma are suitable for anti-TSLP therapy.

The previous history of severe-to-serious exacerbation is an independent factor predicting future exacerbation ( $A O R=3.27)$. This result was consistent with that of a previous study that recent severe asthma exacerbations are an important independent predictor of future severe exacerbation in children with severe/difficult-to-treat asthma ${ }^{44}$. Similarly, a prospective analysis of patients aged $\geq 12$ years with 
severe/difficult-to-treat asthma indicated that recent severe asthma exacerbations appear to be a strong independent factor predicting future exacerbations $(A O R=3.77)^{45}$. These findings should prompt physicians to understand the contributing factors and pathological process driving these exacerbations and refine asthma management to prevent future exacerbation.

Our study has several limitations. First, serial examination of serum biomarkers was not performed to delineate the relationship between changes in biomarkers and asthma control status. Second, all study subjects were under maintenance treatment. Multi-treatment might have influenced the levels of the biomarkers at the initiation of the study. Third, this study was observational in nature, and replicating the results in another cohort is needed. Furthermore, whether the strategy to reduce serum TSLP levels, serum tryptase levels, or blood eosinophil counts in these patients with severe asthma can reduce future development of asthma exacerbation remains to be tested. Therefore, further validation must be performed. Nevertheless, the estimated power (1- $\beta$ ) was 0.99 for our sample size.

\section{Conclusion}

We determined that previous history of severe-to-serious exacerbation, blood eosinophil counts, and serum tryptase and TSLP levels were independently associated with the risk of future exacerbation in severe asthma despite receiving multiple therapy. TSLP and tryptase levels may be implicated in steroid resistance/responsiveness in the asthma inflammatory process. Low serum tryptase levels and high blood eosinophil counts predict the high risk of future asthma exacerbation. These findings should prompt physicians to understand the contributing factors and pathological process driving these exacerbations and refine asthma management to prevent future exacerbation.

\section{Declarations}

\section{Acknowledgements}

The authors are grateful to the KGSupport-Academic Submission Services for assisting with language editing, and Taiwan Clinical Trial Consortium for Respiratory Diseases (TCORE) for the help in planning the study.

\section{Funding}

This work was supported by grant of TSPCCM-20160501A from Taiwan Society of Pulmonary Critical Care Medicine. The funders had no role in the study design, data collection and analysis, or preparation of the manuscript.

\section{Competing interests}

The authors declare no conflict of interest.

\section{Availability of data and material}


The data that support the findings of this study can be obtained from the corresponding author upon reasonable request.

\section{References}

1. Global Initiative for Asthma. Global Strategy for Asthma Management and Prevention. Available from: ginasthma.org (2019).

2. Akinbami, L.J., Moorman, J.E., \& Liu, X. Asthma prevalence, health care use, and mortality: United States, 2005-2009. Natl Health Stat Report. 32, 1-14 (2011).

3. Reddel, H.K., al., American Thoracic Society/European Respiratory Society Task Force on Asthma Control and Exacerbations. An official American Thoracic Society/European Respiratory Society statement: asthma control and exacerbations: standardizing endpoints for clinical asthma trials and clinical practice. Am J Respir Crit Care Med. 180, 59-99 (2009).

4. Calhoun, W.J., al. Clinical burden and predictors of asthma exacerbations in patients on guidelinebased steps 4-6 asthma therapy in the TENOR cohort. J Allergy CLin Immunol Pract. 2, 193-200 (2014).

5. Tay,R., Lee, J.W., \& Hew, M. Diagnosis of severe asthma. Med J Aust.209, S3-S10 (2018).

6. Hekking, P.P., \& Bel, E.H. Developing and emerging clinical asthma phenotypes. J Allergy Clin Immunol Pract. 2, 671-680 (2014).

7. Lötvall, J., et al. Asthma endotypes: a new approach to classification of disease entities within the asthma syndrome. J Allergy Clin Immunol. 127, 355-360 (2011).

8. Carr, T.F., Zeki, A.A., \& Kraft, M. Eosinophilic and noneosinophilic Asthma. Am J Respir Crit Care Med. 197, 22-37 (2018).

9. Pavord, I.D., al. After asthma: redefining airways diseases. Lancet. 391, 350-400 (2018).

10. Barnes, P.J. Targeting cytokines to treat asthma and chronic obstructive pulmonary disease. Nat Rev Immunol. 18, 454-466 (2018).

11. Lambrecht, B.N., \& Hammad, H. The immunology of asthma. Nat Immunol. 16, 45-56 (2015).

12. Sher, E.R., et al. Steroid-resistant asthma. Cellular mechanisms contributing to inadequate response to glucocorticoid therapy. J Clin Invest. 93, 33-39 (1994).

13. Barnes, P.J. Corticosteroid effects on cell signaling. Eur Respir J. 27, 413-426 (2006).

14. Liang, Q., et al. IL-2 and IL-4 stimulate MEK1 expression and contribute to T cell resistance against suppression by TGF-beta and IL-10 in asthma. J Immunol. 185, 5704-5713 (2010).

15. Martin, R.J., al.; National Heart, Lung, and Blood Institute's Asthma Clinical Research Center. The Predicting Response to Inhaled Corticosteroid Efficacy (PRICE) trial. J Allergy Clin Immunol. 119, 7380 (2007).

16. Ziegler, S.F., \& Artis, D. Sensing the outside world: TSLP regulates barrier immunity. Nat Immunol. 11, 289-293 (2010). 
17. Wong, C.K., Hu, S., Cheung, P.F., \& Lam, C.W. Thymic stromal lymphopoietin induces chemotactic and prosurvival effects in eosinophils: implications in allergic inflammation. Am J Respir Cell Mol Biol. 43, 305-315(2010).

18. Kabata, H., al. Thymic stromal lymphopoietin induces corticosteroid resistance in natural helper cells during airway inflammation. Nat Commun 4, 2675 (2013).

19. Pejler, G. The emerging role of mast cell proteases in asthma. Eur Respir J.54, 1900685 (2019).

20. Gao, S., Fan, J., \& Wang, Z. Diagnostic value of serum baseline tryptase levels in childhood asthma and its correlation with disease severity. Int Arch Allergy Immunol. 171, 194-202 (2016).

21. Lin, C.H., al. Budesonide/formoterol maintenance and reliever therapy in asthma control: acute, doserelated effects and real-life effectiveness. Respirology. 20, 264-272 (2015).

22. Krug, N., al. Allergen-induced asthmatic responses modified by a GATA3-specific DNAzymeN. Engl J Med. 372, 1987-1995 (2015).

23. Denlinger, L.C., al.; National Heart, Lung, and Blood Institute's Severe Asthma Research Program-3 Investigators. Inflammatory and comorbid features of patients with severe asthma and frequent exacerbations. Am J Respir Crit Care Med. 195, 302-313 (2017).

24. Price, D.B., et al. Blood eosinophil count and prospective annual asthma disease burden: a UK cohort study. Lancet Respir Med. 3, 849-858 (2015).

25. Green, R.H., et al. Asthma exacerbations and sputum eosinophil counts: a randomised controlled trial. 360, 1715-1721 (2002).

26. Chung, K.F., al. International ERS/ATS guidelines on definition, evaluation and treatment of severe asthma. Eur Respir J. 43, 343-373 (2014).

27. Pellegrino, R., al. Interpretative strategies for lung function tests. Eur Respir J. 26, 948-968 (2005).

28. Chung, K.F. Targeting the interleukin pathway in the treatment of asthma. 386, 1086-1096 (2015).

29. Chung, K.F. Neutrophilic asthma: a distinct target for treatment? Lancet Respir Med. 4, 765-767 (2016).

30. Wagener, A.H., al. External validation of blood eosinophils, $\mathrm{FE}(\mathrm{NO})$ and serum periostin as surrogates for sputum eosinophils in asthma. Thorax. 70, 115-120 (2015).

31. Vedel-Krogh, S., al. Association of blood eosinophil and blood neutrophil counts with asthma exacerbations in the Copenhagen General Population Study. Clinical Chemistry. 63, 823-832 (2017).

32. Stone, K.D., Prussin, C., \& Metcalfe, D.D. IgE, mast cells, basophils, and eosinophils. J Allergy Clin Immunol 125, S73-80 (2010).

33. Balzar, S., al. Mast cell phenotype, location, and activation in severe asthma. Data from the Severe Asthma Research Program. Am J Respir Crit Care Med. 183, 299-309 (2011).

34. Dougherty, R.H., al. Accumulation of intraepithelial mast cells with a unique protease phenotype in T(H)2-high asthma. J Allergy Clin Immunol. 125, 1046-1053 (2010).

35. Kraft, M., al.; Asthma Clinical Research Network. Airway tissue mast cells in persistent asthma: predictor of treatment failure when patients discontinue inhaled corticosteroids. Chest. 124, 42-50 
(2003).

36. Varricchi, G., al. Thymic stromal lymphopoietin isoforms, inflammatory disorders, and cancer. Frontier in Immunol 9, 1595, (2018).

37. Li, Y., al. Elevated expression of IL-33 and TSLP in the airways of human asthmatics In vivo: a potential biomarker of severe refractory disease. J Immunol. 200, 2253-2262 (2018).

38. Berraïes, A., Hamdi, B., Ammar, J., Hamzaoui, K., \& Hamzaoui, A. Increased expression of thymic stromal lymphopoietin in induced sputum from asthmatic children. Immunol Lett. 178, 85-91 (2016).

39. Glück, J., Rymarczyk, B., Kasprzak, M., \& Rogala, B. Increased levels of interleukin-33 and thymic stromal lymphopoietin in exhaled breath condensate in chronic bronchial asthma. J Int Arech Allergy Immunol. 169, 51-56 (2016).

40. Chauhan, A., Singh, M., Agarwal, A., \& Paul, N. Correlation of TSLP, IL-33, and CD 4 + CD $25+$ FOXP3 + T regulatory (Treg) in pediatric asthma. J Asthma. 52, 868-872 (2015).

41. Shikotra, A., al. Increased expression of immunoreactive thymic stromal lymphopoietin in patients with severe asthma. J Allergy Clin Immunol. 129, 104-111 (2012).

42. Liu, S., al. Steroid resistance of airway type 2 innate lymphoid cells from patients with severe asthma: The role of thymic stromal lymphopoietin. J Allergy Clin Immunol. 141, 257-268 (2018).

43. Corren, J., al. Tezepelumab in Adults with Uncontrolled Asthma. N Engl J Med. 377, 936-946 (2017).

44. Haselkorn, T., al. Recent asthma exacerbations predict future exacerbations in children with severe or difficult-to-treat asthma. J Allergy Clin Immunol. 124, 921-927 (2009).

45. Miller, M.K., Lee, J.H., Miller, D.P., \& Wenzel, S.E.; TENOR Study Group. Recent asthma exacerbations: a key predictor of future exacerbations. Respir Med. 101, 481-489 (2007).

\section{Tables}

Table 1. Baseline characteristics of the study subjects $(n=132)$. 


\begin{tabular}{|c|c|c|c|c|}
\hline & $\begin{array}{l}\text { Total } \\
(\mathrm{n}=132)\end{array}$ & $\begin{array}{l}\text { Exacerbation } \\
(n=52)\end{array}$ & $\begin{array}{l}\text { Non- } \\
\text { exacerbation } \\
(n=80)\end{array}$ & $P$ \\
\hline Female (\%) & $82(62)$ & $33(63)$ & $49(61)$ & 0.855 \\
\hline Age (yr) & $\begin{array}{l}62.5(55.0- \\
72.0)\end{array}$ & $\begin{array}{l}60.5(56.4- \\
63.4)\end{array}$ & $\begin{array}{l}63.5(59.5- \\
65.5)\end{array}$ & 0.166 \\
\hline Duration of asthma diagnosis (yr) & $\begin{array}{l}5.0(2.0- \\
12.0)\end{array}$ & $\begin{array}{l}7.0(3.0- \\
16.0)\end{array}$ & $5.0(2.0-12.3)$ & 0.293 \\
\hline Smoking hx (\%) & $39(29)$ & 16(31) & 23(29) & 0.847 \\
\hline Current smoker (\%) & $5(4)$ & $1(2)$ & $4(5)$ & 0.648 \\
\hline Body mass index $\left(\mathrm{kg} / \mathrm{m}^{2}\right)$ & $\begin{array}{l}24.6(22.0- \\
27.7)\end{array}$ & $\begin{array}{l}24.6(22.2- \\
26.9)\end{array}$ & $\begin{array}{l}24.4(21.3- \\
26.7)\end{array}$ & 0.310 \\
\hline Family history of asthma (\%) & $48(36)$ & $21(40)$ & $27(34)$ & 0.464 \\
\hline Atopy (\%) & $72(55)$ & $24(46)$ & $48(60)$ & 0.153 \\
\hline \multicolumn{5}{|l|}{ Comorbidity } \\
\hline Allergic rhinitis (\%) & $95(72)$ & $35(67)$ & $60(75)$ & 0.428 \\
\hline Hypertension (\%) & $60(45)$ & $24(46)$ & $36(45)$ & 1.000 \\
\hline Diabetes mellitus (\%) & $27(20)$ & $9(17)$ & 18(23) & 0.515 \\
\hline GERD (\%) & 23(17) & $9(17)$ & 14(18) & 1.000 \\
\hline Heart failure (\%) & 12(9) & $5(10)$ & $7(9)$ & 1.000 \\
\hline Bronchiectasis (\%) & $6(5)$ & $3(6)$ & $3(4)$ & 0.680 \\
\hline Nasal polyp (\%) & $4(3)$ & $2(4)$ & $2(3)$ & 0.646 \\
\hline \multicolumn{5}{|l|}{ Pulmonary function test } \\
\hline FEV1/FVC (\%) & $\begin{array}{l}66.9(56.8- \\
76.8)\end{array}$ & $\begin{array}{l}66.4(59.2- \\
74.8)\end{array}$ & $\begin{array}{l}66.6(54.8- \\
76.9)\end{array}$ & 0.845 \\
\hline FEV1 (liter) & $\begin{array}{l}1.45(0.96- \\
2.05)\end{array}$ & $\begin{array}{l}1.54(0.96- \\
2.06)\end{array}$ & $\begin{array}{l}1.40(0.99- \\
2.09)\end{array}$ & 0.970 \\
\hline FEV1 \%pred (\%) & $\begin{array}{l}65.3(50.3- \\
80.7)\end{array}$ & $\begin{array}{l}68.0(46.3- \\
80.6)\end{array}$ & $\begin{array}{l}63.0(50.4- \\
80.3)\end{array}$ & 0.543 \\
\hline FVC (liter) & $\begin{array}{l}2.14(1.59- \\
2.91)\end{array}$ & $\begin{array}{l}2.20(1.59- \\
2.94)\end{array}$ & $\begin{array}{l}2.17(1.61- \\
2.96)\end{array}$ & 0.944 \\
\hline FVC \%pred (\%) & $\begin{array}{l}79.6(66.4- \\
94.8)\end{array}$ & $\begin{array}{l}78.0(61.0- \\
95.0)\end{array}$ & $\begin{array}{l}80.1(69.4- \\
106.9)\end{array}$ & 0.495 \\
\hline Positive BDR (\%) & $20(15)$ & $7(13)$ & $13(16)$ & 0.805 \\
\hline
\end{tabular}




\begin{tabular}{|c|c|c|c|c|}
\hline Fixed airflow limitation (\%) & $68(52)$ & $27(52)$ & $41(51)$ & 1.000 \\
\hline \multicolumn{5}{|l|}{ Use of ICS and } \\
\hline LABA (\%) & $91(69)$ & $33(63)$ & $58(73)$ & 0.336 \\
\hline LABA and LAMA (\%) & $31(23)$ & $11(21)$ & $20(25)$ & 0.678 \\
\hline Leukotriene modifier (\%) & $56(42)$ & 19(37) & $37(46)$ & 0.286 \\
\hline Theophylline (\%) & $80(61)$ & $29(56)$ & $51(64)$ & 0.369 \\
\hline Anti-histamine (\%) & $8(6)$ & $2(4)$ & $6(8)$ & 0.479 \\
\hline Maintenance oral prednisolone (\%) & $9(7)$ & 2(4) & $7(9)$ & 0.482 \\
\hline Omalizumab (\%) & $10(8)$ & $4(8)$ & $6(8)$ & 1.000 \\
\hline ACT & $21(19-23)$ & $\begin{array}{l}20.0(18.7- \\
23.0)\end{array}$ & $\begin{array}{l}21.0(18.7- \\
23.0)\end{array}$ & 0.157 \\
\hline Uncontrolled asthma (\%) & $92(70)$ & $39(74)$ & $53(66)$ & 0.335 \\
\hline $\begin{array}{l}\text { Asthma exacerbation in the year prior to } \\
\text { the study }(\%)\end{array}$ & $73(55)$ & $40(77)$ & $33(41)$ & $<0.001$ \\
\hline Severe exacerbation (/yr) & $0.57 \pm 0.74$ & $0.77 \pm 0.75$ & $0.44 \pm 0.70$ & 0.003 \\
\hline Serious exacerbation (/yr) & $0.18 \pm 0.57$ & $0.27 \pm 0.66$ & $0.13 \pm 0.51$ & 0.079 \\
\hline \multicolumn{5}{|l|}{ Asthma exacerbation during 1-year follow-up } \\
\hline Severe exacerbation (/yr) & $0.45 \pm 0.98$ & $1.13 \pm 1.29$ & 0 & $<0.001$ \\
\hline Serious exacerbation (/yr) & $0.29 \pm 1.01$ & $0.71 \pm 1.52$ & 0 & $<0.001$ \\
\hline \multicolumn{5}{|c|}{$\begin{array}{l}\text { Data were reported as mean } \pm \text { standard deviation, median (interquartile range) or number }(\%) \text {. ACT = } \\
\text { asthma control test, BDR = bronchodilator reversibility, FEV } 1 \text { = forced expiratory volume in one } \\
\text { second, FVC = forced vital capacity, GERD = gastroesophageal reflux disease, ICS = inhaled } \\
\text { corticosteroid, LABA = Long-acting beta } 2 \text { agonist, LAMA = long-acting muscarinic antagonist. }\end{array}$} \\
\hline
\end{tabular}

Table 2. Blood cellular and molecular biomarkers in the study subjects $(n=132)$ 


\begin{tabular}{|c|c|c|c|c|}
\hline & $\begin{array}{l}\text { Total } \\
(\mathrm{n}=132)\end{array}$ & $\begin{array}{l}\text { Exacerbation } \\
(n=52)\end{array}$ & $\begin{array}{l}\text { Non-exacerbation } \\
(\mathrm{n}=80)\end{array}$ & $P$ \\
\hline \multicolumn{5}{|l|}{ Cellular markers } \\
\hline WBC (cells/ul) & $7680(6190-9400)$ & $8110(6400-9800)$ & $6900(5945-8550)$ & 0.052 \\
\hline Eosinophil (cells/ul) & $187.6(84.0-365.7)$ & $\begin{array}{l}241.5(248.5- \\
458.0)\end{array}$ & $\begin{array}{l}\text { 166.7(148.8- } \\
225.9)\end{array}$ & 0.016 \\
\hline Eos $\geq 150$ cells/ul (\%) & $81(61)$ & $36(69)$ & $45(56)$ & 0.212 \\
\hline Eos $\geq 300$ cells/ul (\%) & $42(32)$ & $25(48)$ & 17(21) & 0.004 \\
\hline Eos $\geq 4 \%(\%)$ & $43(33)$ & $23(44)$ & $20(25)$ & 0.036 \\
\hline Neutrophil (\%) & $58.9(51.8-66.2)$ & $57.9(49.1-65.0)$ & $59.7(52.6-67.1)$ & 0.232 \\
\hline \multicolumn{5}{|l|}{ Molecular markers } \\
\hline $\operatorname{lgE}, \mathrm{IU} / \mathrm{ml}$ & $101.0(30.1-320.0)$ & $109.3(25.5-296.0)$ & $83.2(41.7-311.0)$ & 0.769 \\
\hline \multirow{2}{*}{$\begin{array}{l}\text { Tryptase beta-2 } \\
(\mathrm{pg} / \mathrm{ml})\end{array}$} & 1053.5 & 768.2 & 1725.5 & \multirow[t]{2}{*}{0.010} \\
\hline & (373.9-2403.3) & $(169.2-1732.8)$ & $(517.1-3036.5)$ & \\
\hline TSLP (pg/ml) & $8.0(3.5-21.1)$ & $16.3(3.4-32.3)$ & 7.1(3.3-18.2) & 0.016 \\
\hline FeNo (ppb) & $26.0(19.3-43.8)$ & $31.0(21.0-43.3)$ & $25.8(18.0-44.7)$ & 0.205 \\
\hline Periostin (pg/ml) & $14.3(9.4-19.8)$ & $16.7(11.4-22.1)$ & $13.0(9.1-18.2)$ & 0.206 \\
\hline IL-5 (pg/ml) & $2.2(1.3-3.0)$ & $2.1(1.1-3.7)$ & $2.3(1.3-3.0)$ & 0.882 \\
\hline IL-13 (pg/ml) & $62.5(35.3-76.0)$ & $63.8(33.3-76.1)$ & $63.2(34.7-77.6)$ & 0.545 \\
\hline IL-33 (pg/ml) & $2.9(1.0-5.0)$ & $3.1(1.2-5.9)$ & $2.9(1.3-4.5)$ & 0.615 \\
\hline TNF-a (pg/ml) & $2.5(1.6-3.6)$ & $2.6(1.3-3.6)$ & $2.4(1.6-3.4)$ & 0.906 \\
\hline IL-8 (pg/ml) & $6.6(4.4-11.7)$ & $6.8(4.5-11.6)$ & $6.7(4.4-13.1)$ & 0.954 \\
\hline IL-17 (pg/ml) & $12.6(9.9-15.6)$ & $12.7(10.4-15.1)$ & $12.7(10.1-15.7)$ & 0.909 \\
\hline TGF- $\beta$ (pg/ml) & $24.9(19.9-33.3)$ & $26.8(21.9-34.2)$ & $22.7(19.3-33.3)$ & 0.063 \\
\hline VEGF (pg/ml) & $\begin{array}{l}267.0(157.9- \\
398.2)\end{array}$ & $\begin{array}{l}281.9(167.7- \\
400.8)\end{array}$ & $\begin{array}{l}266.2(140.3- \\
416.9)\end{array}$ & 0.698 \\
\hline PIGF (pg/ml) & $4.7(3.2-7.7)$ & $4.4(3.2--.7)$ & $5.3(4.0-9.5)$ & 0.471 \\
\hline
\end{tabular}

Data were reported as median (interquartile range) or number (\%). EOS $=$ eosinophil, FeNO $=$ fraction of exhaled nitric oxide, $\mathrm{PIGF}=$ placental growth factor, $\mathrm{TGF}=$ tumor growth factor, $\mathrm{TNF}=$ tumor necrosis factor, $\mathrm{TSLP}=$ thymic stromal lymphopoietin, $\mathrm{VEGF}=$ vascular endothelial growth factor, $\mathrm{WBC}=$ white blood cell. 
Table 3. Significant factors associated with asthma exacerbation $(n=132)$

\begin{tabular}{|lllll|}
\hline & Univariate & \multicolumn{3}{l|}{ Multivariate } \\
\hline Variable & OR $(95 \% \mathrm{Cl})$ & $P$ & $\mathrm{AOR}(95 \% \mathrm{Cl})$ & $P$ \\
\hline $\begin{array}{l}\text { Previous history of severe-to-serious } \\
\text { exacerbation }\end{array}$ & $4.75(2.17-$ & $<0.001$ & $3.27(1.34-$ & 0.009 \\
\hline Serum tryptase $\leq 1448 \mathrm{pg} / \mathrm{mL}$ & $10.40)$ & & $8.00)$ & \\
& $2.47(1.17-$ & 0.009 & $2.53(1.01-$ & 0.048 \\
Serum TSLP $\geq 25 \mathrm{pg} / \mathrm{mL}$ & $5.19)$ & & $6.36)$ & \\
& $6.30(2.41-$ & $<0.001$ & $8.67(2.63-$ & $<0.001$ \\
Blood Eos count $\geq 291 \mathrm{cells} / \mathrm{uL}$ & $16.52)$ & & $28.62)$ & \\
& $2.92(1.38-$ & 0.005 & $6.04(2.30-$ & $<0.001$ \\
\hline
\end{tabular}

EOS $=$ eosinophil, TSLP = thymic stromal lymphopoietin.

\section{Figures}



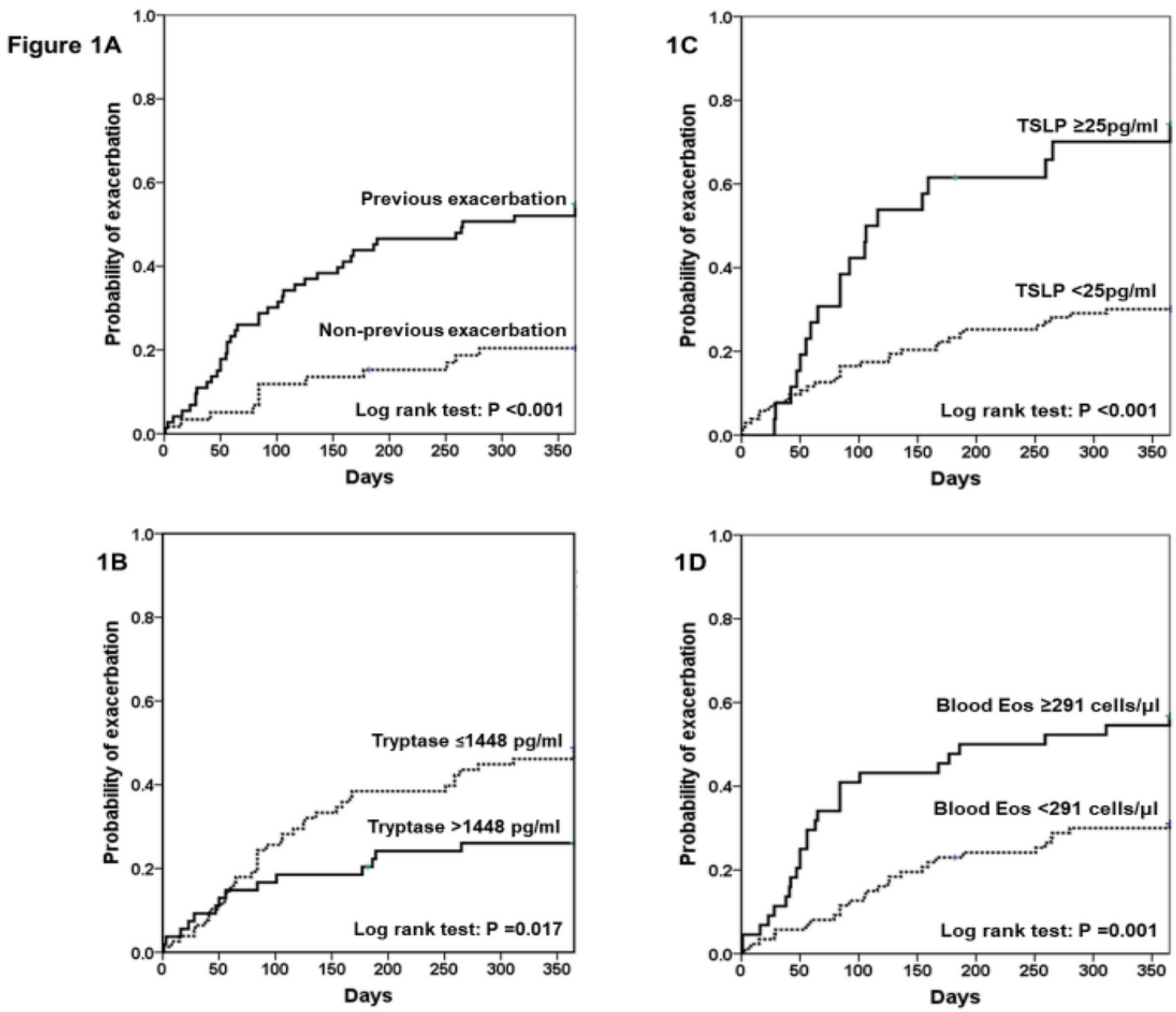

\section{Figure 1}

Kaplan-Meier curves of the cumulative probability of exacerbation during the 1-year follow-up period stratified by previous history of asthma exacerbation (A), serum tryptase (B) and TSLP (C) levels, and blood eosinophil count (D). The cut-off values of $1448 \mathrm{pg} / \mathrm{mL}, 25 \mathrm{pg} / \mathrm{mL}$, and 291 cells $/ \mathrm{uL}$ for serum tryptase level, serum TSLP level, and blood eosinophil count, respectively, were chosen by receiver operating characteristic curve analysis. 

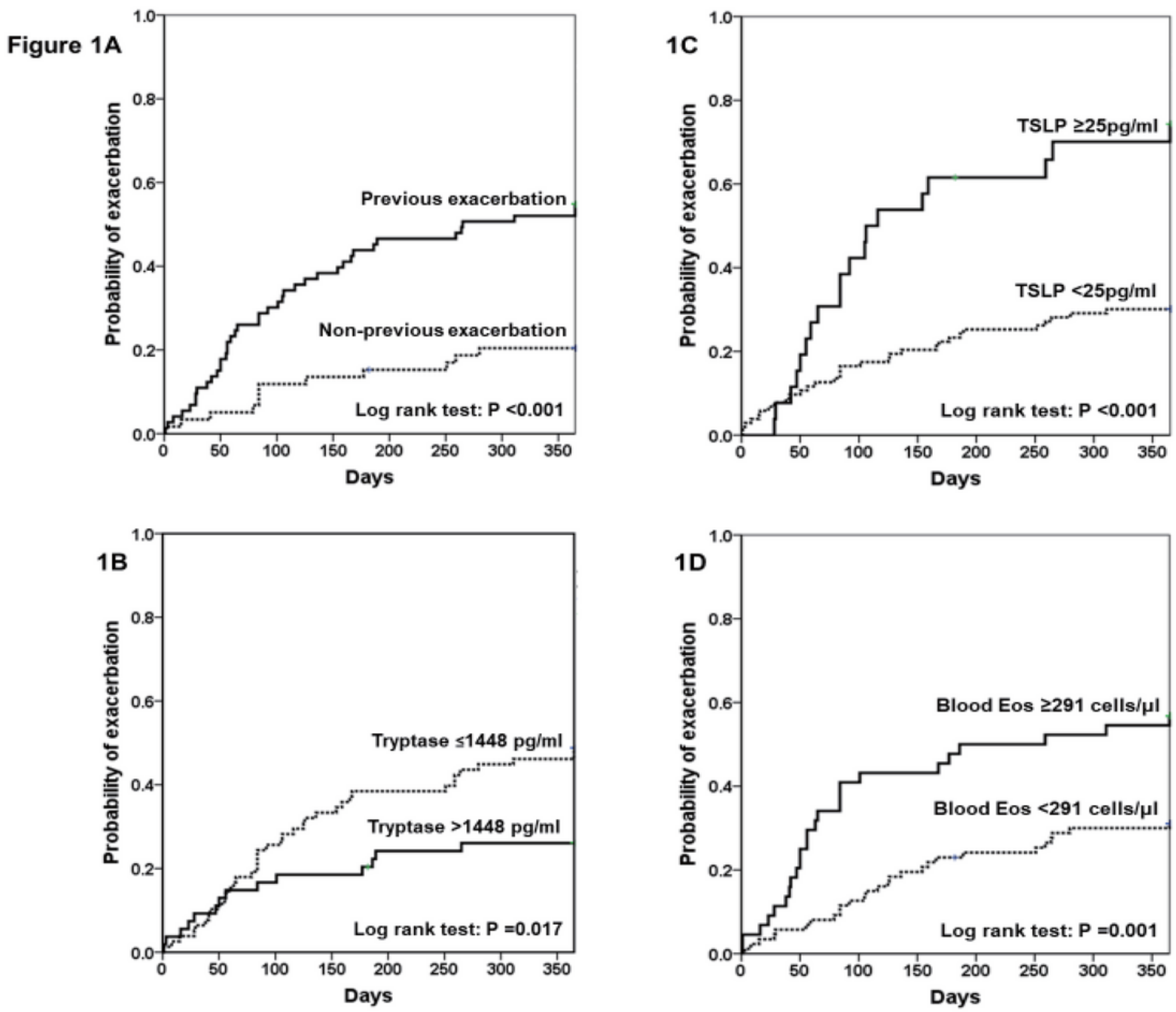

\section{Figure 1}

Kaplan-Meier curves of the cumulative probability of exacerbation during the 1-year follow-up period stratified by previous history of asthma exacerbation (A), serum tryptase (B) and TSLP (C) levels, and blood eosinophil count (D). The cut-off values of $1448 \mathrm{pg} / \mathrm{mL}, 25 \mathrm{pg} / \mathrm{mL}$, and $291 \mathrm{cells} / \mathrm{uL}$ for serum tryptase level, serum TSLP level, and blood eosinophil count, respectively, were chosen by receiver operating characteristic curve analysis. 
9.7 G3 (2.26-41.34)*

\subsection{G2 (1.97-26.63)*}

\section{$1.0 \mathrm{G} 1$}

0

5

10

15

20

25

Tryptase

Eosinophil

Number of Case

Group

L H

22

G4

H

H

22

G3

L

L

41

G2

H

L

32

G1

\section{Figure 2}

Adjusted odds ratio (AOR) for developing asthma exacerbation during the 1-year follow-up period based on blood tryptase and eosinophil levels. High $(\mathrm{H})$ and low $(\mathrm{L})$ levels of serum tryptase and blood eosinophil count were defined on the basis of the cut-off values of $1448 \mathrm{pg} / \mathrm{mL}$ and $291 \mathrm{cells} / \mathrm{uL}$, respectively. * denotes $p$ value $<0.05$. When $\mathrm{G} 1$ group is defined as reference, the AOR with $95 \%$ confidence intervals $(95 \% \mathrm{Cl}$ ) and $\mathrm{p}$ value for asthma exacerbation during the 1-year follow-up period for 
G4, G3, and G2 are $16.92(3.88-73.74, p<0.001), 9.67(2.26-41.34, p=0.002)$, and $7.25(1.97-26.63, p=$ $0.003)$, respectively.

16.9 G4 (3.88- 73.74)*

9.7 G3 $(2.26-41.34) *$

7.3 G2 (1.97-26.63)*

$1.0 \mathrm{G1}$

0

5

10

15

20

25

\begin{tabular}{lll}
\hline Tryptase & Eosinophil Number of Case $\quad$ Group \\
\hline
\end{tabular}

$\begin{array}{llll}\text { L } & \text { H } & 22 & \text { G4 }\end{array}$

H H

22

G3

$\mathbf{L}$

L

41

G2

H

$\mathbf{L}$

32

G1

Figure 2

Adjusted odds ratio (AOR) for developing asthma exacerbation during the 1-year follow-up period based on blood tryptase and eosinophil levels. High $(\mathrm{H})$ and low $(\mathrm{L})$ levels of serum tryptase and blood eosinophil count were defined on the basis of the cut-off values of $1448 \mathrm{pg} / \mathrm{mL}$ and 291 cells/uL, 
respectively. * denotes $p$ value $<0.05$. When $\mathrm{G} 1$ group is defined as reference, the AOR with $95 \%$ confidence intervals $(95 \% \mathrm{Cl}$ ) and $\mathrm{p}$ value for asthma exacerbation during the 1-year follow-up period for G4, G3, and G2 are 16.92 (3.88-73.74, p < 0.001), $9.67(2.26-41.34, p=0.002)$, and $7.25(1.97-26.63, p=$ $0.003)$, respectively.

\section{Supplementary Files}

This is a list of supplementary files associated with this preprint. Click to download.

- FigE1ROCforonlinesupplement600dpi.tif

- FigE1ROCforonlinesupplement600dpi.tif

- supplementalmaterialtitleandauthorname.docx

- supplementalmaterialtitleandauthorname.docx 